\title{
Differences in oxidative response of subpopulations of neutrophils from healthy subjects and patients with rheumatoid arthritis
}

\author{
Paul Eggleton, Ling Wang, John Penhallow, Neville Crawford, K Alun Brown
}

\begin{abstract}
Objectives-To determine whether blood neutrophils from healthy individuals and blood and synovial fluid neutrophils from patients with rheumatoid arthritis (RA) responded differently to priming agonists and stimuli of the oxidative burst and, if so, whether this was a property of a subpopulation of neutrophils.

Methods-Continuous flow electrophoresis was used to separate neutrophils into subpopulations based upon quantitative differences in net negative surface charge. The generation of superoxide anion $\left(\mathrm{O}_{2}^{-}\right)$ was used as a measure of oxidative activity using $10^{-7} \mathrm{~mol} / \mathrm{N}$-formyl-methionylleucyl-phenylalanine (FMLP) as the stimulating agonist and $10^{-8} \mathrm{~mol} / \mathrm{l}$ platelet activating factor (PAF) as the priming agent.
\end{abstract}

Results-The production of $\mathrm{O}_{2}^{-}$by blood and synovial fluid neutrophils from RA patients in response to FMLP was greater than that observed with control blood neutrophils ( $p<0.001)$. Priming of normal blood neutrophils with PAF increased their FMLP induced oxidative burst (p<0.001), but PAF treatment had no effect on rheumatoid neutrophils. Neutrophils from synovial fluid of $R A$ patients were less electronegative than paired blood samples and exposure of blood neutrophils to FMLP but not PAF reduced their surface charge. Continuous flow electrophoresis isolated three neutrophil subpopulations: cells of least surface electronegativity were ascribed to pool P1 and cells of greatest surface electronegativity to P3. Normal blood neutrophils from P3, but not P1, showed increased oxidative activity after PAF priming (twofold increase; $p<0.01$ ), whereas the responsiveness of rheumatoid blood and synovial fluid neutrophils from P1 and P3 was not modified by PAF treatment under the same conditions.

Conclusion-It is suggested that most of the circulating neutrophils in $R A$ are already in a state of readiness to generate $\mathrm{O}_{2}^{-}$upon activation by an inflammatory stimulus. This is in contrast to normal blood neutrophils, which have both responsive and non-responsive subpopulations with respect to priming agonists.

(Ann Rheum Dis 1995; 54: 916-923)
The heavy infiltration of neutrophils into joint cavities with the concomitant release of lysosomal enzymes and reactive oxygen intermediates may underlie the pathological changes that produce joint damage in rheumatoid arthritis. ${ }^{2}$ Several chemotactic and inflammatory factors appear to recruit neutrophils to inflammatory foci, ${ }^{3-8}$ and a feature of many of these mediators is their ability at low concentrations to prime neutrophils for increased production of superoxide anion when subsequently stimulated. From our own observations of neutrophil subpopulation heterogeneity ${ }^{9-14}$ and the studies of others, ${ }^{15-17}$ we propose that within the circulating neutrophil pool, cells coexist at different levels of functional status. Consequently, neutrophil migration through vessel walls adjacent to inflammatory lesions may be selective for a hyperactive subpopulation that is highly responsive to priming agonists and stimulating agents. Moreover, it is likely that some circulating neutrophils are in a resting state whilst others are primed, stimulated or in a primed-stimulated state.

The diversity of agents capable of priming the respiratory burst, some of which may operate synergistically, has made it difficult to identify the different signal pathways involved at the membrane and submembrane level and how they are linked to and regulate intracellular mechanisms. A recent study has shown that physiological priming agents exert their regulatory effects at or distal to $G$ protein activation, but proximal to protein kinase $C$ activation, ${ }^{18}$ suggesting all priming agents act eventually through a common pathway despite their molecular diversity and origins. Several methods have been used to isolate and study subpopulations of neutrophils and other cells in different states of activation. Continuous flow electrophoresis (CFE), which fractionates cells on the basis of differences in surface membrane electrical charge is a relatively mild, reproducible and high resolution procedure. ${ }^{19}$ The direct relationship between cell membrane electrokinetic properties and leucocyte functions ${ }^{19}$ makes this technique appropriate for the isolation of neutrophils of different functional status. All leucocytes possess a net negative surface charge and decreasing the surface charge of monocytes and macrophages enhances their phagocytic activity. ${ }^{20}$ Immature neutrophils, which have a surface charge rich in electronegative sialic acid groups, are less adhesive and phagocytic than mature neutrophils, which have a lower net negative

South Parts Oxford,

Oxford OX1 3QU,

United Kingdom.

26 June 1995 
surface charge. ${ }^{21}$ The demonstration that exposure of neutrophils to agonists such as $N$-formyl-methionyl-leucyl-phenylalanine (FMLP), platelet activating factor (PAF), lactoferrin and C5a results in a decrease in the electrophoretic mobility of the cell ${ }^{22}{ }^{23}$ supports the concept that a reduction in surface charge is associated with increased functional activity. In addition, studies by ourselves ${ }^{14}$ and others ${ }^{24}$ have shown that normal blood neutrophils respond in a heterogeneous manner to stimuli of the oxidative burst.

A major aim of this study was to investigate whether there were differences between neutrophils from control subjects and patients with RA in the production of superoxide anion $\left(\mathrm{O}_{2}^{-}\right)$and to examine the effect of priming on this response. We further sought to establish to what degree subpopulations of neutrophils from RA patients were in a primed or more activated state than cells from healthy individuals. To achieve this aspect of the work, subpopulations of neutrophils were prepared by CFE. The identification of primed and unprimed neutrophil subpopulations may prove to be of value in increasing the understanding of pathogenic mechanisms in RA.

\section{Patients and methods}

PATIENTS AND CONTROIS

Blood was collected from 26 patients with definite or classical rheumatoid arthritis, ${ }^{25}$ who were attending the rheumatology clinics at The Royal London Hospital and Royal Free Hospital, and at the time of the investigation were either receiving non-steroidal antiinflammatory drugs (NSAIDs) or were about to commence other anti-inflammatory treatment. Three patients provided both blood and synovial fluid during one visit to the clinic. Patients with severe disease had early morning stiffness lasting more than two hours and an articular index $>20 .{ }^{26}$ Control blood was taken from healthy laboratory personnel who had previously given their informed consent.

\section{PREPARATION OF NEUTROPHILS FROM BLOOD} AND SYNOVIAL FLUID

Neutrophils were isolated from $40 \mathrm{ml}$ of blood anticoagulated with potassium EDTA $1.5 \mathrm{mg} / \mathrm{ml}$ by a one step isolation procedure using polymorphprep (Nycodenz) according to the manufacturer's instructions. The neutrophils were then washed twice in ice cold Hanks' balanced salt solution (HBSS) and maintained at $4^{\circ} \mathrm{C}$ until required. Synovial fluid was collected by aspiration of knee joints in the course of treatment and incubated with $75 \mathrm{U} / \mathrm{ml}$ hyalase (Type X; Sigma Chemical Co) for 30 minutes at $37^{\circ} \mathrm{C}$. The cell suspension was added to an equal volume of ice cold HBSS during washing to help retard the effect of various inflammatory mediators present in the synovial fluid. The cells were gently washed twice at $400 \mathrm{~g}$ for five minutes. After each wash the supernatants were found to contain mainly mononuclear cells, which were discarded. The pelleted cells, enriched with neutrophils, were resuspended in ice cold isotonic ammonium chloride for 10 minutes to lyse contaminating erythrocytes and maintain osmolarity. This was followed by additional washes in ice cold HBSS; the cells were further maintained in HBSS at $1 \times 10^{7} \mathrm{cells} / \mathrm{ml}$. The purity of neutrophils isolated from blood and synovial fluid was approximately $94 \%$ and $90 \%$, respectively.

\section{Cell surface charge}

Previous work in our group demonstrated that incubation of normal blood neutrophils with hyalase did not modify their surface charge. To determine whether exposure of neutrophils to priming and stimulating agents altered cell surface charge, neutrophils from healthy subjects were divided into three aliquots and either incubated with $10^{-8} \mathrm{mmol} / \mathrm{PAF}$ or $10^{-7} \mathrm{~mol} / \mathrm{h}$ FMLP, or left untreated for 15 minutes at $37^{\circ} \mathrm{C}$. The cells were then formaldehyde fixed to prevent further alteration of membrane constituents, by adding to the suspensions an equal volume of $0.8 \% \mathrm{v} / \mathrm{v}$ formaldehyde in HBSS $(0.4 \% \mathrm{v} / \mathrm{v}$ final concentration). The suspension was then left to stand at room temperature for 30 minutes. The fixed cells were maintained in HBSS at $4^{\circ} \mathrm{C}$ until required for separation by $\mathrm{CFE}$.

SEPARATION OF SUBPOPULATIONS OF NEUTROPHILS BY CONTINUOUS FLOW ELECTROPHORESIS

Continuous flow electrophoresis was used to fractionate purified preparations of blood neutrophils from eight RA patients and eight healthy controls. A detailed description of the principles of CFE has been presented elsewhere. ${ }^{19}$ Figure $1 \mathrm{~A}$ illustrates the apparatus used (Elphor Vap 22 CFE apparatus; Bender and Hobein, Munich, Germany) and figure 1B shows typical CFE separation profiles of formaldehyde fixed and unfixed neutrophils from a healthy donor. Briefly, neutrophils were resuspended in a chamber buffer $(10 \mathrm{mmol} / 1$ triethanolamine, $280 \mathrm{mmol} / \mathrm{l}$ glycine and $30 \mathrm{mmol} / \mathrm{l}$ glucose) at a concentration of $2.5 \times 10^{7} \mathrm{cell} / \mathrm{ml}$ and introduced by a continuous flowing film of buffer into the chamber of the apparatus. The cell suspension was injected into the chamber at a flow rate of $2.5 \mathrm{ml} / \mathrm{h}$ and the chamber flow rate was maintained at $4.5 \mathrm{ml} / \mathrm{h}$. The current was set at $100 \mathrm{~mA}$, which gave a potential across the chamber of 900-1000 V. Triethanolamine, EDTA and all other routine reagents were of analytical grade and purchased from $\mathrm{BDH}$. The electrode buffer consisted of $100 \mathrm{mmol} / \mathrm{/}$ triethanolamine and the chamber was held at a constant temperature of $10^{\circ} \mathrm{C}$. The mean peak fraction number was determined by turbidometric analysis in a spectrophotometer at an absorbance of $500 \mathrm{~nm}$ and confirmed by Coulter counting. Fractionated neutrophils were found in approximately 12 to 15 collecting tubes. Many of these tubes contained cells in concentration less than 1 
million and therefore several of them were pooled, on the basis of differences in net tions of approximately equal cell number (P1, P2, and P3). The least and most electronegative pools, $\mathrm{P} 1$ and $\mathrm{P} 3$ respectively, were washed in HBSS before being assayed at the same time as an aliquot of non-fractionated (total pool) cells for $\mathrm{O}_{2}^{-}$production during both stimulated and primed-stimulated conditions.

MEASUREMENT OF SUPEROXIDE PRODUCTION FROM PRIMED AND STIMULATED NEUTROPHILS Aliquots of isolated neutrophils $\left(1 \times 10^{6} \%\right.$ $100 \mu \mathrm{l})$ maintained in $\mathrm{Ca}^{2+}$ and $\mathrm{Mg}^{2+}$ containing HBSS were suspended in $900 \mu \mathrm{l}$ of prewarmed HBSS containing $0.1 \mathrm{mmol} / \mathrm{l}$ cytochrome $c, 5 \mathrm{mmol} / \mathrm{l}$ glucose with and without $50 \mu \mathrm{g} / \mathrm{ml}$ superoxide dismutase (SOD) $(178 \mathrm{U} / \mathrm{ml})$ and placed in temperature controlled cuvettes of a spectrophotometer (Pye Unicam SP8-400). Cells were stimulated to generate superoxide by addition of various concentrations of FMLP $\left(10^{-6}-10^{-8} \mathrm{~mol} / \mathrm{l}\right)$.

Platelet activating factor was used as the priming agent of choice, at a concentration negative charge, into three major subpopula-

$\left(10^{-8} \mathrm{~mol} / \mathrm{l}\right)$ that was previously demonstrated to be optimal for neutrophil priming. ${ }^{27}$ Blood neutrophils from six control subjects and six RA patients were exposed to PAF by the addition of PAF $10^{-8} \mathrm{~mol} / 1$ to the prewarmed cells for two minutes before the addition of FMLP $10^{-7} \mathrm{~mol} / 1$. During this period, baseline activity was monitored at $550 \mathrm{~nm}$ to ensure PAF did not directly stimulate production of superoxide. In control experiments, cells were stimulated without priming.

On addition of FMLP, superoxide activity was measured over a period of five minutes and expressed as $\mathrm{nmol} / \mathrm{min} / 10^{7}$ cells calculated from an extinction coefficient for reduced cytochrome $c$ of $21.2 \times 10^{3}(\mathrm{~mol} / \mathrm{l})^{-1} \mathrm{~cm}^{-1}$.

Cytochrome $c$ (horse heart, type VI), FMLP, PAF, and SOD (from bovine erythrocytes) were purchased from Sigma Chemical Co.

\section{STATISTICS}

The data were analysed using either paired Student's $t$ test (subpopulation comparisons) or Wilcoxon test (healthy subjects $v$ RA patients), using Statsworks 1.3 Cricket Software Inc, PA, USA. All values are

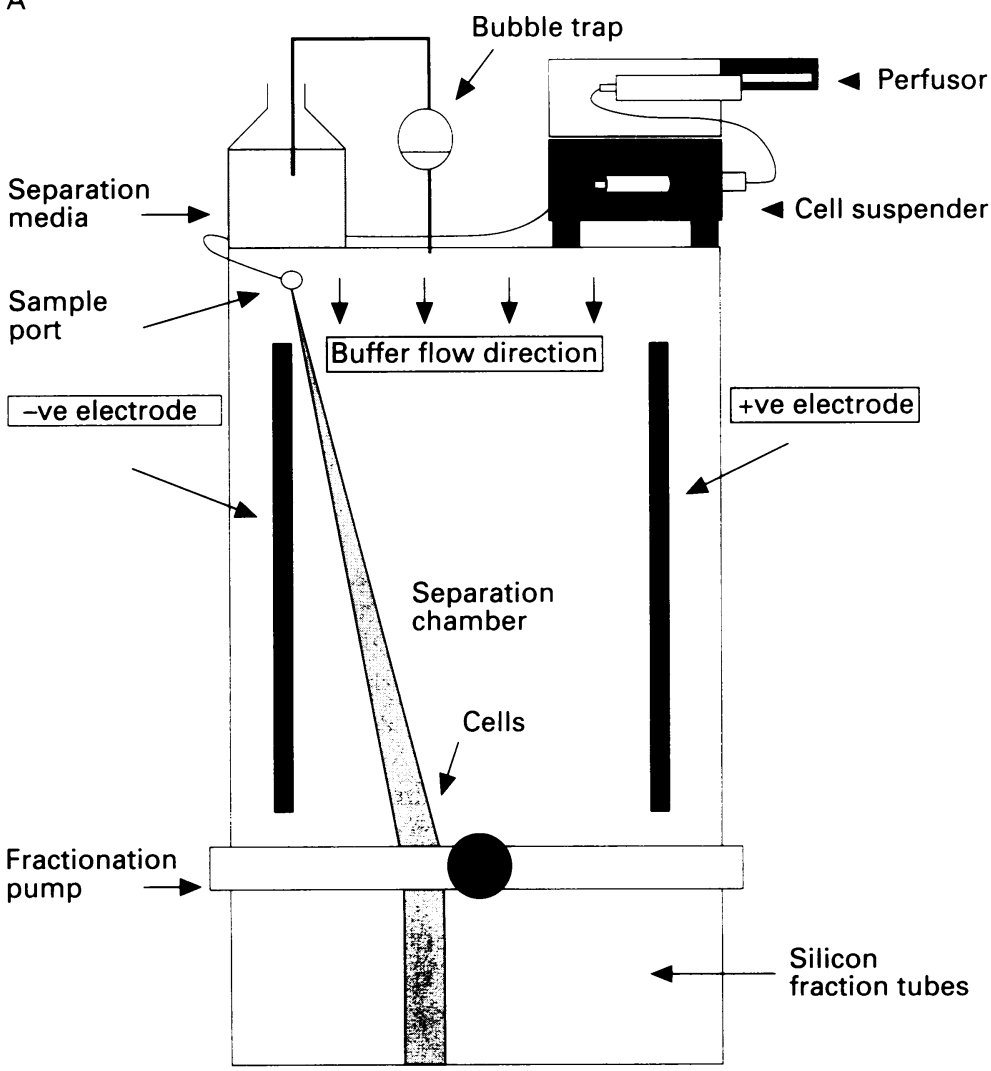

Figure 1 A: Schematic diagram of the CFE chamber and the isolation of neutrophil subpopulations. Neutrophils flow through the CFE chamber between two electrodes and collect in sample tubes. Tubes on the left contain neutrophils which displayed the least deflection in the electrical field (the lowest net negative surface charge). B: Typical CFE separation profile of non-fixed (O) and formaldehyde fixed (O) neutrophils from a healthy donor. The cells in each fraction are counted and pooled into three fractions of approximately equal cell numbers-P1 (least), P2, and P3 (most)

Sample collection tubes 
Table 1 Mean fraction number of CFE separated neutrophils from control and $R A$ peripheral blood

\begin{tabular}{lll}
\hline Subject & \multicolumn{2}{l}{ Peak mean fraction number } \\
\cline { 2 - 3 } & $\begin{array}{ll}\text { Control } \\
\text { neutrophils }\end{array}$ & $\begin{array}{l}\text { RA patient } \\
\text { neutrophils }\end{array}$ \\
\hline 1 & 43 & 27 \\
2 & 38 & 35 \\
3 & 40 & 36 \\
4 & 37 & 31 \\
5 & 37 & 29 \\
6 & 32 & 34 \\
7 & 22 & 28 \\
Mean (SEM) & $36(2 \cdot 7)$ & $31(1 \cdot 4)$ \\
\hline
\end{tabular}

expressed as mean (SEM); the threshold for statistical significance is $\mathrm{p}<0.05$.

\section{Results}

CELL SURFACE CHARGE

Neutrophils fixed in formaldehyde showed an electrophoretic profile similar to that of fresh neutrophils isolated from the same individual (fig 1B).

CFE fractionated blood neutrophils from both control subjects and RA patients exhibited comparable isolation profiles, which ranged from broad to slightly skewed to the left. Interestingly, irrespective of the profile, the peak mean number of cells were generally of a lower electrophoretic mobility in the RA samples (table 1). Within each experiment, the isolated cells did not always appear in the same numbered collecting tubes because individual blood samples were separated on different days, when small variations occurred in buffer composition, $\mathrm{pH}$, conductivity, osmolarity, and electrical conditions. However, on the basis of differences in electronegative charge, the neutrophils always separated into approximately 12 to 15 fractions (collecting tubes).

Neutrophils derived from the blood and synovial fluid of three patients with RA and fractionated on the same day under identical conditions showed a substantial cathodal shift in the separation profiles of those from synovial fluid compared with autologous blood (fig 2).

Priming alone did not alter the cell surface charge properties of blood neutrophils from healthy subjects, but FMLP stimulation led to a cathodal shift in their charge properties (fig 3). The electrokinetic profiles of these cells resembled those of synovial fluid neutrophils (fig 2), in that they appeared to have an overall decrease in net surface charge characteristics when compared with non-treated autologous blood.

COMPARISON OF BLOOD NEUTROPHILS FROM HEALTHY SUBJECTS AND RA PATIENTS FMLP stimulated generation of superoxide

Table 2 shows the production of $\mathrm{O}_{2}^{-}$by blood neutrophils from six control subjects and six patients with severe $R A$, in response to stimulation by $10^{-6}-10^{-8} \mathrm{~mol} / 1$ FMLP. At $10^{-7} \mathrm{~mol} / 1 \mathrm{FMLP}$, the rate of $\mathrm{O}_{2}^{-}$production for RA patients was significantly greater than that for controls $(p>0.001)$. When $10^{-8}$ or $10^{-6} \mathrm{~mol} / \mathrm{l}$ FMLP was used as the stimulus
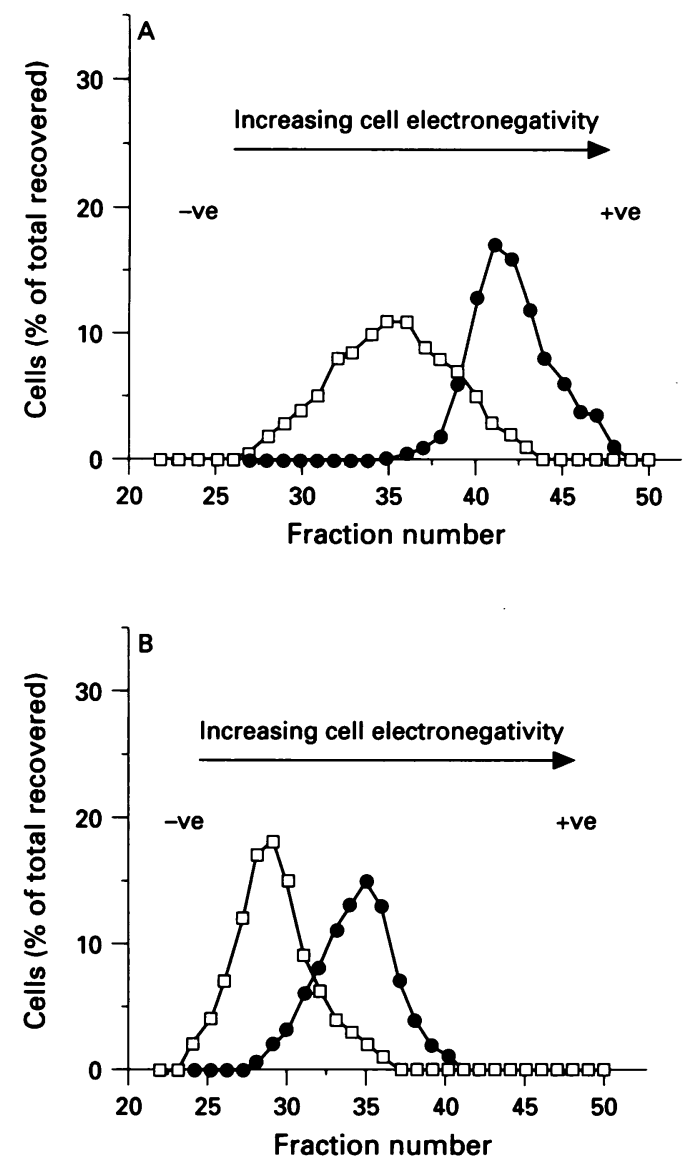

Figure 2 Differences in surface charge for formaldehyde fixed blood (O) and synovial fluid ( $\square$ ) neutrophils from two patients with $R A$ as determined by $C F E$.

there was no significant difference between the two groups. Accordingly, a concentration of $10^{-7} \mathrm{~mol} / 1$ FMLP was considered optimal for distinguishing differences between the two sources of neutrophils and was therefore used throughout the study. FMLP concentrations of $10^{-6}-10^{-8} \mathrm{~mol} / 1$ were not studied further as it was reasoned that, if these concentrations of FMLP could not distinguish differences between whole populations of neutrophils from control and RA subjects, they would be unlikely to identify differences between the P1 and $\mathrm{P} 3$ subpopulations in response to FMLP

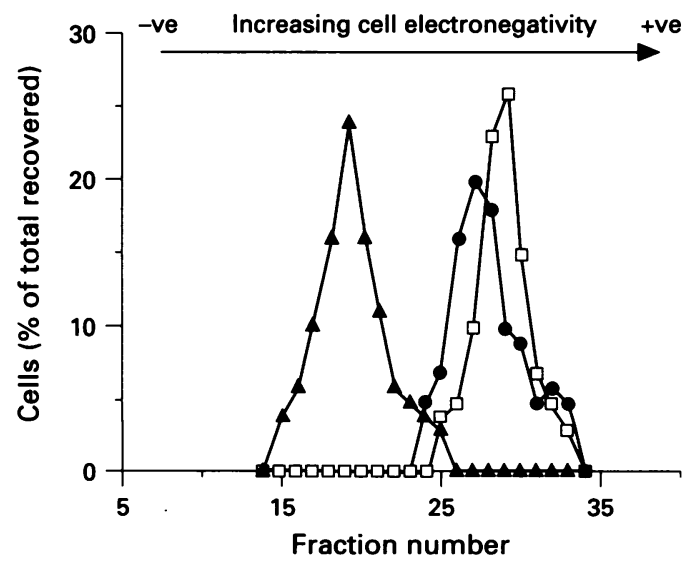

Figure 3 Effect of priming and stimulation on surface charge properties of blood neutrophils from a healthy subject that were untreated at $37^{\circ} \mathrm{C}$ for 15 minutes (O), primed for 15 minutes with $10^{-8}$ moll $P A F$ at $37^{\circ} \mathrm{C}$ ( $\square$ ), or stimulated for 15 minutes with $10^{-7}$ moll FMLP at $37^{\circ} \mathrm{C}$ (A) before fixation by formaldehyde and fractionation by CFE. 
Table 2 Dose response effects of FMLP on the rate of superoxide production by neutrophils isolated from six healthy controls $(C)$ and six patients with severe rheumatoid arthritis $(R A)$

\begin{tabular}{|c|c|c|c|c|c|c|}
\hline \multirow[t]{3}{*}{ Subject } & \multicolumn{6}{|c|}{ Superoxide (nmolmin $/ 10^{7}$ cells) } \\
\hline & \multicolumn{2}{|c|}{$\begin{array}{l}F M L P \\
10^{-6} \mathrm{~mol} /\end{array}$} & \multicolumn{2}{|c|}{$\begin{array}{l}F M L P \\
10^{-7} \mathrm{moln}\end{array}$} & \multicolumn{2}{|c|}{$\begin{array}{l}F M L P \\
10^{-8} \mathrm{~mol} /\end{array}$} \\
\hline & C & $R A$ & C & $R A$ & $C$ & $R A$ \\
\hline 1 & 44 & 45 & 28 & 44 & 5 & 10 \\
\hline 2 & 46 & 58 & 20 & 41 & 5 & 18 \\
\hline 3 & 48 & 55 & 38 & 52 & 2 & 10 \\
\hline 4 & 40 & 51 & 26 & 57 & 4 & 13 \\
\hline 5 & 31 & 44 & 25 & 55 & 5 & 13 \\
\hline 6 & 35 & 53 & 20 & 49 & 14 & 9 \\
\hline Mean & 41 & 51 & 26 & $50^{\star}$ & 6 & 12 \\
\hline SEM & $2 \cdot 4$ & $2 \cdot 2$ & $2 \cdot 6$ & $2 \cdot 5$ & $1 \cdot 7$ & 1.5 \\
\hline
\end{tabular}

Values are mean of duplicate measurements.

* Significant difference between neutrophils from RA patients and control neutrophils with $10^{-7} \mathrm{~mol} / 1$ FMLP $(p<0.001$ unpaired Student's $t$ test) (no difference with $10^{-8}$ or $10^{-6} \mathrm{~mol} /$ FMLP)

stimulation. Analysis of neutrophils from a further 17 healthy subjects and $14 \mathrm{RA}$ patients with mild or moderate disease activity again revealed the patients' cells to be more efficient than control cells at producing $\mathrm{O}_{2}^{-}$(mean 39.2 (SEM $4 \cdot 7$ ) $\mathrm{nmol} / \mathrm{min} / 10^{7}$ cells in RA patients compared with $22.5 \quad(1.7) \mathrm{nmol} / \mathrm{min} / 10^{7}$; $\mathrm{p}<0.001$, Wilcoxon test) (fig 4). There was a considerable variation in the range of $\mathrm{O}_{2}^{-}$ production in response to $10^{-7} \mathrm{~mol} / \mathrm{l}$ FMLP by blood neutrophils from control subjects $\left(12-38 \mathrm{nmol} / \mathrm{min} / 10^{7}\right.$ cells) and from patients with RA (25-94 nmol/min/ $10^{7}$ cells).

\section{Effect of priming with $P A F$}

$\mathrm{O}_{2}^{-}$production by normal neutrophils was significantly enhanced with PAF, increasing from a mean $\mathrm{O}_{2}^{-}$production of $27 \cdot 6($ SEM $2 \cdot 4)$ $\mathrm{nmol} / \mathrm{min} / 10^{7}$ cells without PAF to $41 \cdot 2(2 \cdot 3)$ $\mathrm{nmol} / \mathrm{min} / 10^{7}$ cells $(\mathrm{p}<0.001)$ after priming with PAF (fig $5 \mathrm{~A}$ ). In contrast, priming had no significant effect on $\mathrm{O}_{2}^{-}$production by rheumatoid neutrophils (fig $5 \mathrm{~B}$ ).

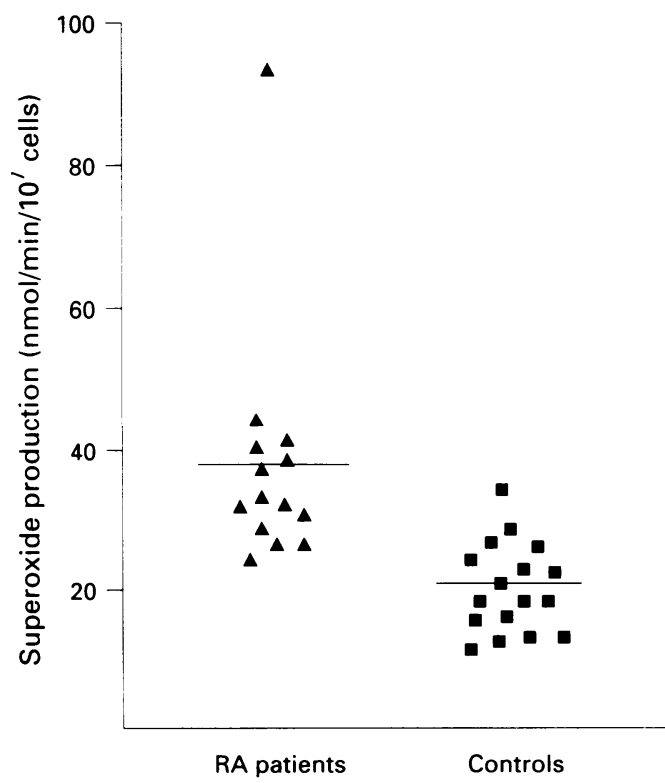

Figure 4 Production of superoxide by unfractionated rheumatoid and healthy control blood neutrophils stimulated by $10^{-7}$ moll FMLP. Horizontal bars represent mean value for each group. Significant difference between group means $(p<0.001)$.
COMPARISON OF ELECTROPHORETICALLY SEPARATED SUBPOPULATIONS OF NEUTROPHILS The amount of $\mathrm{O}_{2}^{-}$generated by the $\mathrm{Pl}$ fraction pool of normal neutrophils in response to $10^{-7} \mathrm{~mol} / 1 \mathrm{FMLP}$ was significantly greater than (up to twice) the amount generated by the P3 fraction which contained the most electronegative cells $(p<0.001)$ (fig 6$)$. The P1 and P3 subpopulations of RA neutrophils did not differ significantly in their FMLP stimulated responsiveness, though both pools produced more $\mathrm{O}_{2}^{-}$than the corresponding control subpopulations $(\mathrm{p}<0.01)$. A similar finding occurred with the P1 and P3 subpopulations of neutrophils from rheumatoid synovial fluid (table 3 ).

\section{Effect of priming with $P A F$}

With control neutrophils, the $\mathrm{O}_{2}^{-}$production by the P3 subpopulation was significantly increased by PAF treatment (table $3, p<0.01$ ) whereas priming had no effect on the P1 subpopulation. Pretreatment of the P1, P3, and unfractionated cells from RA blood and synovial fluid with PAF did not enhance their responsiveness to FMLP stimulation. However, the production of $\mathrm{O}_{2}^{-}$by rheumatoid blood and synovial fluid neutrophils in P1 and P3 was greater than that of P1 and P3 control samples $(p<0.01)$.
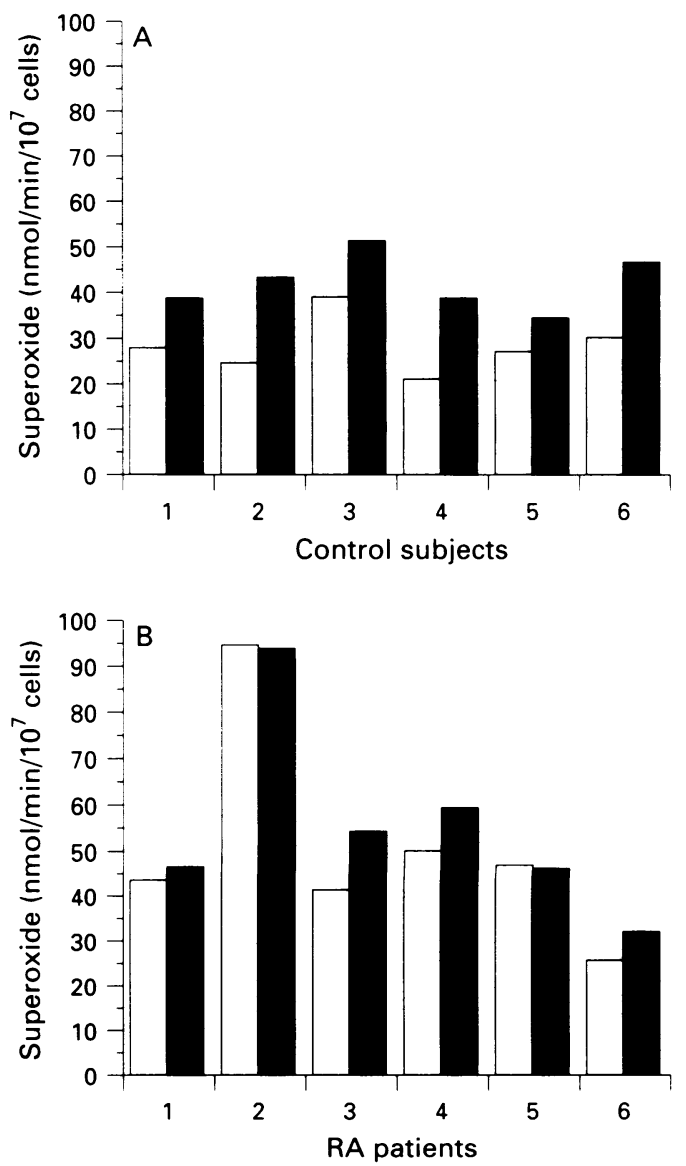

Figure 5 Effect of priming with platelet activating factor (PAF) on superoxide anion production by unfractionated six healthy control $(A)$ and six rheumatoid $(B)$ samples of blood neutrophils primed ( $\square$ ) or not primed ( $\square$ ) with $P A F$ before stimulation with $10^{-7}$ mol/ FMLP. Significant effect of priming between normal and rheumatoid neutrophils $(p<0.001)$. 


\section{Discussion}

Superoxide anion production by neutrophils, which is believed to contribute to both defence against microbial invasion and tissue damage, is regulated by priming of the cells with physiological agonists such as leukotriene B4, interleukin, granulocyte macrophage colony stimulating factor, tumour necrosis factor, and PAF. $^{3-7}$ In the present study, blood neutrophils from rheumatoid patients in various stages of disease activity had higher rates of $\mathrm{O}_{2}^{-}$ production than cells from healthy individuals in response to stimulation by $10^{-7} \mathrm{~mol} / 1 \mathrm{FMLP}$, but not with higher $\left(10^{-6} \mathrm{~mol} / \mathrm{l}\right)$ or lower $\left(10^{-8} \mathrm{~mol} / \mathrm{l}\right)$ concentrations of FMLP. It therefore appears that the concentration of stimulant is important in detecting differences in $\mathrm{O}_{2}^{-}$production by neutrophils from these two subject groups; this probably explains why previous studies using $10^{-6} \mathrm{~mol} / / \mathrm{FMLP}$ failed to show a difference between oxidative responsiveness of neutrophils from RA and control subjects. ${ }^{28}{ }^{29}$ Priming of the rheumatoid cells with PAF did not augment their
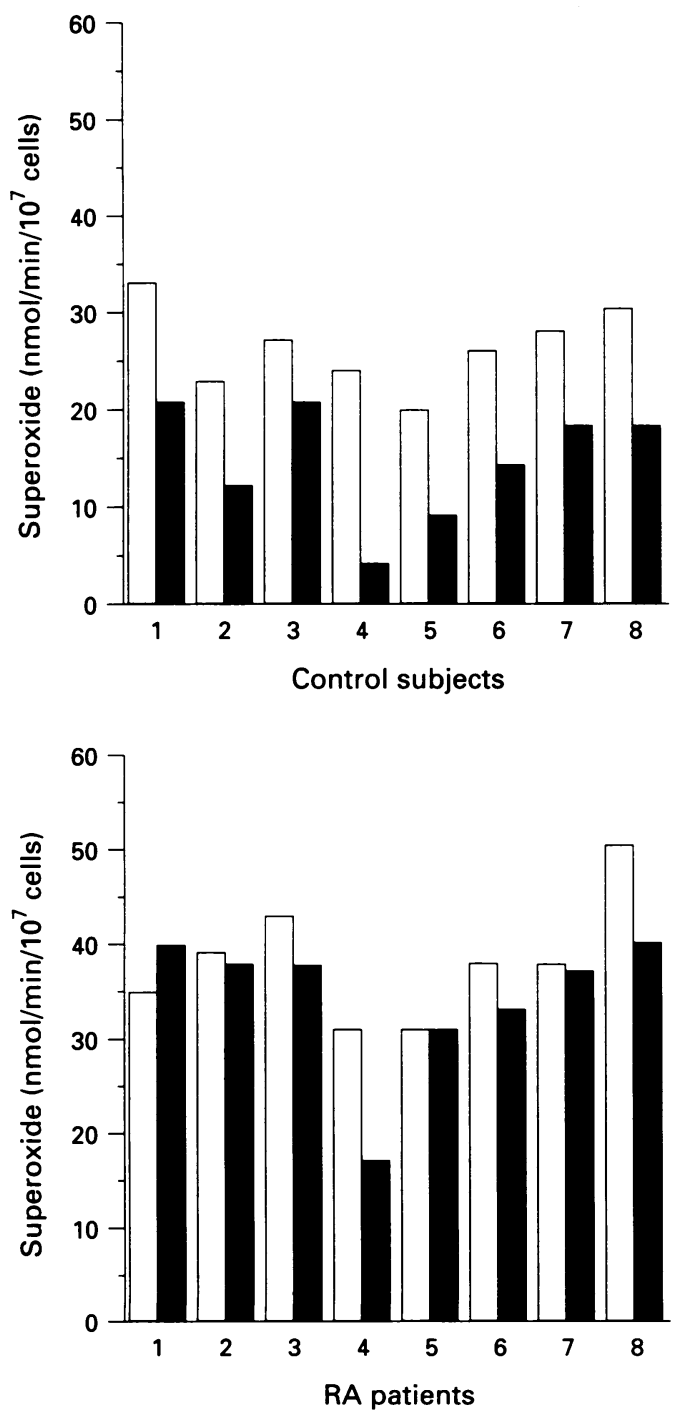

Figure 6 Production of superoxide anion by electrophoretic subpopulations of blood neutrophils from eight healthy subjects $(A)$ and eight $R A$ patients $(B)$, fractionated by $C F E$ into $P 1$ and $P 3$ subpopulations. Significantly greater production of superoxide anion by both $P 1$ and $P 3$ subpopulations of $R A$ compared with corresponding control subpopulations $(p<0.01) . \square=P 1$ : least electronegative subpopulations $(p<0 \cdot 01) . \square=P 1$ : least
cells $\mathbf{Q}=$ P3: most electronegative cells.
Table 3 Ability of unfractionated neutrophils and the least (P1) and most (P3) electronegative CFE fractionated subpopulations of neutrophils from control and $R A$ subjects to respond to priming with $P A F 10^{-8}$ moll after stimulation with $10^{-7}$ moln FMLP

\begin{tabular}{|c|c|c|c|c|c|c|}
\hline \multirow[t]{3}{*}{ Subjects } & \multicolumn{6}{|c|}{ Superoxide (nmolmin $/ 10^{7}$ cells) } \\
\hline & \multicolumn{2}{|c|}{ Least -ve (P1) } & \multicolumn{2}{|c|}{ Most -ve (P3) } & \multicolumn{2}{|c|}{ Total pool } \\
\hline & $S$ & $P / S$ & $S$ & $P / S$ & $S$ & $P / S$ \\
\hline \multicolumn{7}{|c|}{ Control blood neutrophils } \\
\hline 1 & 17 & 19 & 5 & 21 & 17 & 24 \\
\hline 2 & 27 & 25 & 12 & 24 & 15 & 19 \\
\hline 3 & 19 & 23 & 11 & 20 & 21 & 25 \\
\hline Mean & 21 & 22 & 9 & $18^{\star}$ & 18 & 23 \\
\hline SEM & $3 \cdot 1$ & $1 \cdot 8$ & $2 \cdot 2$ & $1 \cdot 7$ & $1 \cdot 7$ & $1 \cdot 8$ \\
\hline \multirow{2}{*}{\multicolumn{7}{|c|}{$\begin{array}{l}\text { RA subjects } \\
\text { Blood neutrophils }\end{array}$}} \\
\hline & & & & & & \\
\hline 1 & 32 & 36 & 29 & 24 & 25 & 37 \\
\hline 2 & 44 & 40 & 35 & 42 & 35 & 30 \\
\hline 3 & 38 & 45 & 30 & 38 & 32 & 35 \\
\hline Mean & 38 & 40 & 31 & 35 & 31 & 34 \\
\hline SEM & 3.5 & $2 \cdot 6$ & 1.8 & $5 \cdot 5$ & 2.9 & $2 \cdot 1$ \\
\hline \multicolumn{7}{|c|}{ Synovial fluid neutrophils } \\
\hline & 44 & 48 & 45 & 45 & 47 & 51 \\
\hline & 58 & 64 & 67 & 59 & 57 & 55 \\
\hline Mean & 51 & 56 & 56 & 52 & 52 & 53 \\
\hline
\end{tabular}

$\mathrm{S}=$ Stimulated with $10^{-7} \mathrm{~mol} / \mathrm{FMLP}$ alone; $\mathrm{P} / \mathrm{S}=$ primed with $10^{-8} \mathrm{~mol} / \mathrm{PAF}$ and stimulated with $10^{-7} \mathrm{~mol} / \mathrm{hMLP}$ (P/S).

* Significant response to priming $(p<0.01)$ by $\mathrm{P} 3$ subpopulation of healthy controls; P1 subpopulation from controls and $\mathrm{P} 1$ and $\mathrm{P} 3$ subpopulations from RA blood and synovial fluid unresponsive to priming.

responsiveness, in contrast to the enhancing effect of PAF on control neutrophils. With greater concentrations of FMLP, pretreatment of control cells with PAF did not increase their oxidative burst (data not shown), presumably because the rate of $\mathrm{O}_{2}^{-}$generation induced by the stimulant alone was at its optimum level. At present it is unclear why the primed and stimulated control neutrophils did not reach the high rates of production of $\mathrm{O}_{2}^{-}$seen with RA neutrophils challenged only with $10^{-7} \mathrm{~mol} / \mathrm{l}$ FMLP. Rheumatoid blood may contain many inflammatory mediators and it is conceivable that, in this disease, circulating neutrophils are primed in vivo by agents that are more potent than those used in in vitro studies. Alternatively, there may be synergistic effects which have not yet been explored.

A particular feature of this study was the identification of subpopulations of normal blood neutrophils which differed in their respiratory burst in response to priming agonists and stimulation. The subpopulation containing the least electronegative neutrophils was the most responsive to a 'stimulant' only challenge. Priming of these cells with PAF did not enhance their generation of $\mathrm{O}_{2}^{-}$production by FMLP, which was in contrast to the neutrophils with a high net negative surface charge, which exhibited significant increases in responsiveness following PAF priming. These findings add support to the concept that there is functional and metabolic heterogeneity within neutrophils, ${ }^{9-17}$ and that the magnitude of these parameters relates inversely to surface membrane electronegativity. In addition, our studies agree with the recent proposal that in healthy individuals there are at least two populations of circulating neutrophils which differ from one another in their response to priming agents. ${ }^{18}$

Using two physically distinct cell separation techniques (continuous flow electrophoresis 
and partitioning in two phase aqueous polymer systems), our earlier studies showed that blood neutrophils are heterogeneous with respect to cell surface membrane electrokinetic properties and functional responsiveness. ${ }^{13} 14$ Our previous work also demonstrated that neutrophils of a low electrophoretic mobility were increased in the blood and particularly in the synovial fluid of RA patients, ${ }^{911}$ and that immune complexes reduced the surface charge of normal blood neutrophils. ${ }^{30}$ In the present study, rheumatoid synovial fluid neutrophils separated by CFE were found to be of a consistently lower electrophoretic mobility than autologous blood neutrophils. Neutrophils within rheumatoid joints are reported to be activated as judged by their $\mathrm{O}_{2}^{-}$production $^{28}{ }^{29}$ and receptor expression. ${ }^{31}$ The current demonstration that normal blood neutrophils stimulated with FMLP, but not those primed with PAF, possessed a low electrophoretic mobility similar to that expressed by synovial fluid neutrophils, strengthens the association of low surface charge with cell activation. The cathodal shift in profile observed with $10^{-7} \mathrm{~mol} / \mathrm{I}$ FMLP appears to be concentration dependent. When $5 \times 10^{-9} \mathrm{~mol} / 1$ FMLP was used instead (data not shown), there was no observable change in the shape or peak position of the CFE profile.

Why electrophoretic subpopulations of normal neutrophils differ in their production of $\mathrm{O}_{2}^{-}$remains to be resolved. Little attention has focused on the relationship between the functional status of cells and their surface charge, even though a reduction in the electrophoretic mobility of neutrophils by foreign or natural polycations leads to an increased responsiveness to stimulants, ${ }^{30}$ and neuraminidase increases phagocytic activity. ${ }^{20}$ Surface charge heterogeneity may arise from subpopulations of different stem cell origin, from late maturational differences emerging before and after entry into the circulation, ${ }^{15}$ or as a result of cytokines, primers, stimulants, and other factors acting on the cell surface to initiate membrane reorganisation. Examination of electrophoretic subpopulations of neutrophils in the present study revealed that priming with PAF enhanced the respiratory burst activity of only the P3 subpopulation (most electronegative) from control blood neutrophils. The inability of PAF to increase superoxide production of the other subpopulations of control and RA neutrophils in response to FMLP suggests that these cells were at their maximum threshold of responsiveness under the present experimental conditions. Furthermore, upon activation, the $\mathrm{P} 1$ and $\mathrm{P} 3$ subpopulations of RA blood and synovial fluid neutrophils produced higher levels of superoxide anion than control cells, implying that these cells had been influenced by one or several in vivo inflammatory factors. This in part would explain why the heterogeneity seen in normal controls is not detectable in RA cells, as exposure of these latter cells to a number of inflammatory agents before isolation may have enhanced the functional responsiveness of these cells above control levels. In addition to surface charge, it is likely that rheumatoid neutrophils differ from control cells in receptor expression and that their surface and functional properties are modified by the effect of in vivo factors such as immune complexes and, in relation to synovial fluid neutrophils, apoptosis. Future studies are planned to examine these possibilities. Although NSAIDs are known to suppress a number of neutrophil functions, to date there is no information to suggest that cell surface properties are modified by these drugs. The implications of neutrophil heterogeneity are considerable in the context of infection and tissue damage, where the rapid extravasation of a primed subpopulation of cells would benefit the acute inflammation but, if continued, would exacerbate the chronic inflammatory response. Unravelling the mechanisms by which neutrophils become activated and their recruitment into the joint cavities of patients with rheumatoid arthritis, by the combined application of CFE with other biochemical and functional techniques promises to be a useful approach, once changes in electronegativity are more clearly defined and understood.

We are grateful to the Arthritis and Rheumatism Council of Great Britain for financial support. We also acknowledge the help and advice of Dr L Poulter and his clinical colleagues in the Department of Rheumatology, Royal Free Hospital School the Department of Rheumatology, Royal Free Hospital School The Royal London Hospital.

1 Babior B M. Oxidants from phagocytes: agents of defense and destruction. Blood 1984; 64: 959-66.

2 Brown K A. The polymorphonuclear cell in rheumatoid arthritis. Br $\mathcal{f}$ Rheumatol 1988; 27: 150-5.

3 Gay J C, Beckman J K, Brash A R, Oates J A, Lukens J N. Enhancement of chemotactic factor-stimulated neutrophil oxidative metabolism by leukotrine B4. Blood 1984 64: 780-5.

4 Sample A K, Czuprynski C J. Priming and stimulation of bovine neutrophils by recombinant interleukin-1 $\alpha$. f Leukoc Biol 1991; 49: 107-15.

5 Jaswon M S, Khwaja A, Roberts P J, Jones H M, Linch D C. The effect of rhGM-CSF on the neutrophil respiratory burst when studied in whole blood. $B r y$
Haematol 1990; 75: 181-7.

6 Test S T. Effect of tumor necrosis factor on the generation of chlorinated oxidants by adherent human neutrophils. f Leukoc Biol 1991; 50: 131-9.

7 Vercellotti G M, Yin H Q Gustafson, K S, Nelson R D, Jacob H S. Platelet activating factor primes neutrophil responses to agonists: role in promoting neutrophilmediated endothelial damage. Blood 1988; 71: 1100-7.

8 Eggleton P, Penhallow J, Crawford N. Priming action of inositol hexakisphosphate (InsP6) on the stimulated respiratory burst in human neutrophils. Biochim Biophys Acta 1991; 1094: 309-16.

9 Brown K A, Collins A J, Holborow E J. Cell electrophoretic analysis of lymphocytes and polymorphonuclear cells from patients with rheumatoid arthritis. Lancet 1977; i: from patien.

10 Spangenberg $P$, Crawford N. Surface membrane electrokinetic properties of polymorphonuclear leucocytes: subpopulation heterogeneity and phagocytic competence. f Cell Biochem 1987; 34: 259-268.

11 Brown K A, Perry J D, Black C, Dumonda D C Identification by cell electrophoresis of a subpopulation of polymorphonuclear cells which is increased in patients with theumatoid arthritis and certain other rheumatological disorders. Ann Rheum Dis 1988; 47: 353-8.

12 Crawford N, Eggleton P, Fisher D. Population heterogeneity in blood neutrophils fractionated by continuous flow electrophoresis (CFE) and by partitioning in aqueous polymer two phase system (PAPS). In: Kompala D S, Todd S, eds. Cell separation (PAPS). In: Kompala D S, Todd S, eds. Cell separation Science and technology. Washington

13 Eggleton P, Crawford N, Fisher D. Fractionation of human neutrophils into subpopulations by countercurrent distributions: surface charge and functional heterogeneity. Eur I Cell Biol 1992; 57: 265-272.

14 Eggleton P, Fisher D, Crawford N. Heterogeneity in the circulating pool: studies on subpopulation separated by circulating pool: studies on subpopulation separated by continuous flow

15 Gallin, J I. Human neutrophil heterogeneity exists, but is it meaningful? Blood 1984; 63: 977-83. 
16 Smith D M, Hanes B, Johnson J A, Turner R A. Functional and metabolic heterogeneity among normal neutrophil subpopulations. F Clin Lab Anal 1988; 3: 174-83.

17 Bass D A, Olbrantz P, Szejda P, Seeds M C, McCall C E. Subpopulations of neutrophils with increased oxidative
product formation in blood of patients with infection. product formation in blood

18 Daniels R H, Elmore M A, Hill M E, Shimizu Y, Lackie $J$ M, Finnen M J. Priming of the oxidative burst in human neutrophils by physiological agonists or cytochalasin B results from the recruitment of previously non-responsive cells. Immunology 1994; 82: 465-72.

19 Preece A W, Brown K A. Recent trends in particle electrophoresis. Chrambach A, Dunn M J, Radola B J, eds. In: Advances in electrophoresis. VCH Weinheim, 1989; 349-404.

20 Weiss L Mayhew E, Ulrich A. The effect of neuraminidases on the phagocytic process in human monocytes. Lab

21 Litchman M A, Weed R I. Alteration of the cell periphery during granulocyte maturation: relationship to cell function. Blo

22 Gallin J I. Degranulating stimuli decrease the negative surface charge and increase adhesiveness of human neutrophils. F Clin Invest 1980; 65: 298-306.

23 Ingraham $L M$, Coates $T$, Allen J M, Higgins $C P$, Baehner R L, Boxer L A. Metabolic, membrane and functional responses of human polymorphonuclear leukocytes to platelet activating factor. Blood 1982; 59: 1259-66.

24 Elbim C, Collet-Martin S, Bailly S, Harkim J, Gougerot M A. Priming of polymorphonuclear neutrophils by tumour necrosis factor alpha in whole blood: identification of two polymorphonuclear subpopulations in response to formyl-peptides. Blood 1993; 82: tions in

25 Ropes M W, Bennett G A, Cobb S, Jacox R, Jesser R A. Revision of diagnostic criteria for theumatoid arthritis. Revision of diagnostic criteria

26 Ritchie D M, Boyle J A, McInnes J M, et al. Clinical studies with an articular index for the assessment of joint tenderness in patients with rheumatoid arthritis. $Q \mathcal{F} M e d$ 1968; 37: 393-406.

27 Eggleton P, Ghebrehiwet B, Coburn J P, Sastry K N, Zaner K S, Tauber A I. Characterization of the human neutrophil C1q receptor and functional effects of free ligand on activated neutrophils. Blood 1994; 84: 1640-9.

28 Dularay B, Elson C J, Dieppe P A. Enhanced oxidative response of polymorphonuclear leukocytes from synovial fluids of patients with rheumatoid arthritis. Autoimmunity 1988; 1: 159-69.

29 Nurcombe H L, Bucknall R C, Edwards S W. Neutrophils isolated from the synovial fluid of patients with rheumatoid arthritis: priming and activation in vivo. $A n n$ Rheum Dis 1991; 50: 147-53.

30 Brown K A, McCarthy D, Perry J D, Dumonde D C. Reduction of the surface charge of blood polymorphonuclear cells by rheumatoid sera and heat induced aggregated human IgG (HAGG). Ann Rheum Dis 1988; 47: 359-63.

31 Watson F, Robinson J J, Phelan M, Bucknall R C, Edwards $S$ W. Receptor expression in synovial fluid neutrophils from patients with theumatoid arthritis. Ann Rheum Dis 1993; 52: 354-9. 